\title{
Bacterial pigments and its significance
}

\begin{abstract}
Pigments are compounds that are widely used in industries that come in a wide variety of colors, some of which are water-soluble. Nontoxic nature of pigment produced by a number of microorganisms make them environmentally friendly for utilization in dye, foodstuff, pharmacy, cosmetics and other industrial purposes. Moreover natural pigments produced from biological origin have medicinal importance as been used as antioxidant, antimicrobial, additives, color intensifiers, and anticancer as well as economically friendly. Some of Bacteria capable of producing pigment with different varieties of colors are Agrobacterium aurantiacum, Staphylococcus aureus, Chromobacterium violaceum, Serratia marcescens, Bacillus Spp, Flavobacterium sp, etc. colors are Pink-red, Golden Yellow, Purple, red, Creamy and yellow respectively. Industrial production of natural food colorants by microbial fermentation has several advantages such as cheaper production, easier extraction, higher yields through strain improvement, no lack of raw materials and no seasonal. Therefore the present study aimed at reviewing pigment produced by bacteria and its significance.
\end{abstract}

Keywords: bacterial pigments, microorganism, antioxidants, non-toxic, antimicrobial activities, biocolorants
Volume 4 Issue 3 - 2017

\author{
Hizbullahi M Usman, Nafi'u Abdulkadir, \\ Mustapha Gani, Hauwa'u M Maiturare \\ Microbiology Department Sokoto State University, Nigeria
}

Correspondence: Nafi'u Abdulkadir, Microbiology Department Sokoto State University, Along Birnin Kebbi road near Airport Sokoto State Nigeria,

Email nafiuabdulkadir523@gmail.com

Received: October 03, 2017 | Published: December 28, 2017

\section{Introduction}

Pigments are compounds with characteristics of importance to many industries. In the food industry they are used as additives, color intensifiers, antioxidants, etc. Pigments come in a wide variety of colors, some of which are water-soluble. ${ }^{1}$ The production colorant from biological agents for food and textile has attracted increased interests in recent years. Nature produces many biocolorants from various resources including plants and microorganisms, which are possible alternatives to synthetic dyes and pigments currently employed. ${ }^{2}$ The recent awareness in human safety and environmental conservation has made fresh enthusiasm for natural sources of colors. Natural colorants or dyes derived from flora and fauna are believed to be safe because of non-toxic, non-carcinogenic and biodegradable in nature. ${ }^{3}$ As the present trend throughout the world is shifting towards the use of eco-friendly and biodegradable commodities, the demand for natural colorants is increasing in every day.

Natural pigments are sourced from ores, insects, plants and microbes. Biopigments produced from microorganisms are preferred over those from plants because of their stability ${ }^{4}$ and availability for cultivation throughout the year. ${ }^{5}$ Among microbes, bacteria have immense potential to produce diverse bioproducts and one such bioproduct is pigments. The production and application of bacterial pigments as natural colorants has been investigated by various researchers. ${ }^{6,7}$ Bacterial pigment production is now one of the emerging field of research to demonstrate its potential for various industrial applications. ${ }^{8}$ Most of the bacterial pigment production is still at the R\&D stage. Hence, work on the bacterial pigments should be intensified especially in finding cheap and suitable growth medium which can reduce the cost and increase its applicability for industrial production. ${ }^{6}$ The utilization of natural pigments in foodstuff, dyestuff, cosmetics and pharmaceutical manufacturing processes has increased in the recent years due to their non-toxic nature. Moreover, their ecofriendly, antioxidant, anticancer and antimicrobial activities further add to their positive effects. The significant growth in the naturally derived colors has been attributed to their stability and consumer perception. Further the annual growth rate of naturally derived colors has been predicted to be 5-10 per cent in comparison to synthetic colors with a low growth rate of 3-5 percent. ${ }^{9}$ There is growing interest in microbial pigments due to their natural character and safety to use, medicinal properties, nutrients like vitamins, production being independent of season and geographical conditions, and controllable and predictable yield. ${ }^{10}$ Again bacterial pigments can be produced from waste material thus environmental pollution (Table 1). ${ }^{7,11}$

\section{Advantages of bacterial pigments}

Pigments produced by bacteria are of traditional use in oriental countries and have been a subject of intense research in the present decades because of its potential for applications. Bacterial pigments offer the following benefits and advantages as follows:

a. Increasingly attractive to science because of broad ranging activities.

b. Easy propagation and wide strain selection.

c. High versatile and productive over other sources.

d. Fermentation is inherently faster and more productive compared to any other chemical process.

e. Easy to manipulate genes.

f. Simple and fast culturing techniques allowing continuous bioreactor operation.

g. Structural complexity suits for industrial needs.

h. Bacterial pigments extracted using simple liquid-liquid extraction technique minimizing operation cost.

i. Cheap substrates used for bulk production. 


\section{Role in food industries}

The development of foods with an attractive appearance is an important goal in the food industry. Increasingly, food producers are turning to natural food colors, since certain artificial color additives have demonstrated negative health issues following their consumption. Due to the lack of availability of natural food colorants, its demand is much especially in food industry. This demand can be fueled by research to offer a more natural healthy way of coloring foods and provide a clean label declaration. ${ }^{12}$ It is therefore, essential to explore various natural sources of food grade colorants and their potentials. Though many natural colors are available, bacterial colorants play a significant role as food coloring agent, because of its production and easy down-streaming process. Industrial production of natural food colorants by microbial fermentation has several advantages such as cheaper production, easier extraction, higher yields through strain improvement, no lack of raw materials and no seasonal variations. ${ }^{11}$ Bacteria could be genetically modify by inserting genes coding for the colorants even colorants not naturally produced by bacteria.
These pigments are looked upon for their safe use as a natural food colorants and will not only benefit human health but also preserved the biodiversity, as harmful chemicals released into the environment while producing synthetic colorants could be stopped. ${ }^{13}$

Scientists have isolated food grade pigments from bacteria and blue pigment from cultured soil bacteria and could offer a natural colour with an excellent stability and toxicology profile for food. The researchers from the East China University of Science and Technology reported that the blue pigment taps into the trend for edible natural pigments. ${ }^{14}$ Bacterial colours were already used in fish industry to enhance the pink colour of farmed salmon. Further, some natural food colorants have commercial potential for use as antioxidants. ${ }^{15}$ Thus bacterial colorants in addition to being environment friendly, can also serve the dual need for visually appealing colours and probiotic health benefits in food products. ${ }^{16}$ They are considered safe and approved by FDA. The successful marketing of pigments derived from bacteria, both as a food colour and a nutritional supplement depend on consumer safety and freshness of the products.

Table I Pigment producing bacteria."

\begin{tabular}{|c|c|c|}
\hline Microorganisms (Bacteria) & Pigments/Molecule & $\begin{array}{l}\text { Colourl } \\
\text { Appearance }\end{array}$ \\
\hline Agrobacterium aurantiacum & Astaxanthin & Pink-red \\
\hline Paracoccus carotinifaciens & Astaxanthin & Pink-red \\
\hline Bradyrhizobium specie & Canthaxanthin & Dark- red \\
\hline Flavobacterium specie, Paracoccus zeaxanthinifaciens & Zeaxanthin & Yellow \\
\hline Achromobacter & Zeaxanthin & Creamy \\
\hline Bacillus & Zeaxanthin & Brown \\
\hline Brevibacterium specie & Zeaxanthin & Orange Yellow \\
\hline Corynebacterium michigannise & Zeaxanthin & $\begin{array}{l}\text { Greyish to } \\
\text { Creamish }\end{array}$ \\
\hline Corynebacterium insidiosum & Indigoidine & Blue \\
\hline Rugamonas rubra, Streptoverticillium rubrireticuli,Vibrio gaogenes, Alteromonas rubra & Prodigiosin & Red \\
\hline Rhodococcus maris & & Bluish-Red \\
\hline Xanthophyllomyces dendrorhous & Astaxanthin & Pink-Red \\
\hline Haloferax alexandrinus & Canthaxanthin & Dark Red \\
\hline Staphylococcus aureus & $\begin{array}{l}\text { Staphyloxanthin, } \\
\text { Zeaxanthin }\end{array}$ & Golden Yellow \\
\hline Chromobacterium violaceum & Violacein & Purple \\
\hline Serratia marcescens, Serratia rubidaea, & Prodigiosin & Red \\
\hline Pseudomonas aeruginosa & Pyocyanin & Blue-Green \\
\hline Xanthomonas oryzae & Xanthomonadin & Yellow \\
\hline Janthinobacterium lividum & Violacein & Purple \\
\hline
\end{tabular}

\section{Role in pharmaceutical industry}

Most studies investigated that bacteria have shown the efficacy and the potential in clinical applications and their pigment has been used in treating several diseases and they also have certain properties like anti-biotic, anticancer, and immunosuppressive compounds. Significant progress has been achieved in this field, and investigations of bioactive compounds produced by these microbes are rapidly increasing. As such, the number of compounds isolated from bacteria is increasing faster when compared with artificial counterpart. ${ }^{17}$ Anthocyanins are involved in a wide range of biological activities. ${ }^{18}$ Decrease the risk of cancer. ${ }^{19}$ Reduce inflammatory insult ${ }^{20}$ and modulate immune response..$^{21}$ The genus, Serratia can produce a red substance called prodigiosin, these substances have been known to have an antibiotic and antimalarial effect and immunosuppressing activity. $^{22}$ Immunosuppressive activity of prodigiosin was first 
described by Nakamura and co-workers in 1989. These researches showed the presence of prodigiosin and metacycloprodigiosin in culture broth of Serratia and observed selective inhibition of polyclonal proliferation of $\mathrm{T}$-cells as compared to that of $\mathrm{B}-$ cells. Besides that, the cytotoxic potency of prodigiosin has also been investigated in the standard 60 cell line panels of human tumor cells derived from lung, colon, renal, ovarian, brain cancers, melanoma and leukemia. Inhibition of cell proliferation as well as induction of cell death has been observed in these cell lines.

In vitro anticancer activity has also been reported for prodigiosin analogs and synthetic derivative of prodigiosin. The anti-proliferative and cytotoxic effects of prodigiosin have been observed not only in cultured tumor cell lines but also in human primary cancer cells from B-cell chronic lymphocytic leukemia patients. ${ }^{23}$ The use of prodigiosin for treating diabetes mellitus has also been reported by Hwanmook et al. ${ }^{22}$ where prodigiosin was found to be an active component for preventing and treating diabetes mellitus. Violacein is produced by several bacterial species, including the Gram-negative species Chromobacterium violaceum, Janthinobacterium lividum and Pseudoalteromonas luteoviolacea. ${ }^{24}$ Violacein was reported to have antiprotozoan. ${ }^{25}$ Anticancer, ${ }^{26,27}$ Antiviral, ${ }^{28}$ Antibacterial, ${ }^{29}$ and antioxidant activities. ${ }^{30}$ Mojib et al. ${ }^{31}$ described the antimycobacterial activity of two pigments, violacein from Janthinobacterium specie and flexirubin from Flavobacterium specie might be valuable compounds for chemotherapy of tuberculosis. These characteristics provide the possible applications of violacein for therapeutic purposes. ${ }^{32}$ Thus pigments from bacteria offer the wide range of biologically active properties and continue to provide promising avenues to end enormous challenge of antibiotic resistant.

\section{Role in dying industry}

The textile industry produces and uses approximately 1.3 million tons of dyes, pigments and dye precursors, valued at around U\$23 billion, almost all of which is manufactured synthetically. However, synthetic dyes have some limitations, primarily, their production process requires hazardous chemicals, creating worker safety concerns, they may generate hazardous wastes, and these dyes are not environment friendly. ${ }^{33}$ Biosynthesis of colorants (natural dyes) for textile applications has attracted increased interests in recent years. ${ }^{2}$ Krishna et al. ${ }^{34}$ have evaluated the pigments called prodigiosin from marine Serratia $s p$. for application as dye in the textile industry. The results of the study indicated that pigment could be used as natural dye for imparting red color to various grades of textile materials. The color was observed to be stable after wash performance studies. Alihosseini et al..$^{35}$ characterized the bright red pigment prodigiosin from Vibrio spp. and suggested that it could be used to dye many fibers including wool, nylon and silk. Yusof ${ }^{36}$ reported the capability of using pigment from Serratia marcescens to color five types of fabric namely acrylic, polyester microfiber, polyester, silk and cotton using tamarind as mordant. Similar textile-dyeing ability was also reported for Janthinobacterium lividum by Shirata et al. ${ }^{37}$ and gave good color tone when applied on silk, cotton and wool and nylon and vinylon (dark blue, both synthetic fibers).

Ahmad et al. $^{6}$ characterized the red pigment prodigiosin from Serratia marcescens and violet pigment violacein from Chromobacterium violaceum and tested its dyeing efficiency in different fabrics i.e. pure cotton, pure silk, pure rayon, silk satin and polyester. Their results suggested that prodigiosin could be used to dye acrylic and for violacein intense colorations was observed in pure rayon and silk satin. Ahmad et al. ${ }^{6}$ observed the potentiality of prodigiosin and violacein in batik making. Kumar et al.$^{38}$ reported that red pigment prodigiosin from Vibrio sp. Serrtia $s p$. violet pigment from Chromobacterium violaceum, anthraquinone from Dermocybe sanguine, pink pigments from Roseomonas fauriae and Fusarium oxysporum, Trichoderma sp. and Alternaria sp. are suitable for in textile industry for dyeing of all fibers including cotton, wool, silk, nylon and acrylic fibers.

\section{Current limitation and future perspective}

Bacterial pigments are one of the pleasing fields of research in life sciences to demonstrate their applications in various industries. Certain limitations such like high cost investment required for large scale production, lower stability, variations in shades due to some operational parameters, less percentage in terms of annual production, specifications in terms of bacteria capable of producing some colours and technological imperfection lead to delay in progress for industrial production of pigment from bacteria and extraction of pure and concentrated forms are drawing back the effort of researchers to replace synthetic pigments with bacterial pigments produced from biological origin. Studies should be concern especially on finding the easiest method for harvesting bacterial pigments in order to increase their industrials applications. Also there is a need to look on various operational parameters that may cause a variation due to change and develop a new low cost process for the production of bacterial pigments by using agrowaste as substrate in the future. Future investigation on various technologies that would reduce the cost and increase yields for large scale production.

\section{Conclusion}

Nature is rich in colour, and pigment producing microorganisms (fungi, yeasts, bacteria). Microbial pigments are not only used as food colorant, flavouring agent and dying agents they are widely applied in medicinal aspects. The emergence of strains of bacteria resistant to antibacterial agents has become one of the most important problems in clinical medicine. The search for new antibiotic is always on. Out of all the secondary metabolites having antibiotic activity, pigments are the least studied group. As the reports for pigments having antibiotic like activity are rapidly increasing, they should be studied for selective toxicity so that they can be produced commercially for human use.

\section{Acknowledgements}

None.

\section{Conflict of interest}

The author declares no conflict of interest.

\section{References}

1. Tibor C. Liquid Chromatography of Natural pigments and synthetic dyes. J Chromatography Library. 2006;71:602.

2. Mapari SA, Nielsen KF, Larsen TO, et al. Exploring fungal biodiversity for the production of water-soluble pigments as potential natural food colorants. Curr Opin Biotechnol. 2005;16(2):231-238.

3. Cristea D, Vilarem G. Improving light fastness of natural dyes on cotton yarn. Dyes and Pigments. 2006;70(3):238-245.

4. Raisainen R, Nousiainen P, Hynninen PH. Dermorubin and 5-chlorodermorubin natural anthraquinone carboxylic acids as dyes for wool. Textile Research Journal. 2002;72(11):973-976. 
5. Parekh S, Vinci VA, Strobel RJ. Improvement of microbial strains and fermentation processes. Appl Microbiol Biotechnol. 2000;54(3):287301 .

6. Ahmad AS, Ahmad WYW, Zakaria ZK, et al. Applications of bacterial pigments as colorant. The Malaysian perspective, Springer Briefs in Molecular Science. New York, USA; 2012. 77 p.

7. Joshi VK, Attri D, Bala A, et al. Microbial pigments. Ind Journal of Biotechnolog. 2003;2:362-369.

8. Venil CK, Lakshmanaperumalsamy P. An insightful overview on microbial pigment: prodigiosin. Ele J Biol. 2009;5(3):49-61.

9. Parmar M, Phutela UG. Biocolors: The New Generation Additives. Int J Curr Microbiol App Sci. 2015;4(7):688-694.

10. Nakashima T, Kurachi M, Kato Y, et al. Characterization of bacterium isolated from the sediment at coastal area of omura bay in Japan and several biological activities of pigment produced by this isolate. Microbiol Immunol. 2005;49(5):407-415.

11. Kamla M, Jayanti T, Sneh G. A review on microbial pigment. Int J Microbial Res Technol. 2012;1(4):361-365.

12. Aberoumand A. A review article on edible pigments properties and sources as natural biocolorants in foodstuff and food industry. World J Dairy Food Sci. 2011;6(1):71-78.

13. Bener M, Özyürek M, Güc lü K, et al. Polyphenolic contents of natural dyes produced from industrial plants assayed by HPLC and novel spectrophotometric methods. Ind Crop Prod. 2010;32(3):499-506.

14. Jensen MB, López-de-Dicastillo Bergamo CA, Payet RM, et al. Influence of copigment derived from Tasmannia pepper leaf on Davidson's plumanthocyanins. J Food Sci. 2011;76(3):C447-C453.

15. Dufosse L. Pigments, microbial. Schaechter, Moselio. Encyclopedia Microbiol. 2009:457-471.

16. Venkatasubramanian S, Vijaeeswarri J, Anna Lakshmi J. Effective natural dye extraction from different plant materials using ultrasound. Ind Crops Prod. 2011;33(1):116-122.

17. Soliev AB, Hosokawa K, Enomoto K. Bioactive pigments from marine bacteria applications and physiological roles. Evid Based Complement Alternat Med. 2011;2011(2011):1-17.

18. Kong JM, Chia LS, Koh NK, et al. Analysis and biological activities of anthocyanins. Phytochemistry. 2003;64(5):923-933.

19. Kim HW, Kim JB, Cho SM, et al. Anthocyanin changes in the Korean purple-fleshed sweet potato, Shinzami, as affected by steaming and baking. Food Chem. 2012;130(4):966-972.

20. Yuodim KA, McDonald J, Kalt W, et al. Potential role of dietary flavonoids in reducing microvascular endothelium vulnerability to oxidative and inflammatory insults (small star, filled). $J$ Nutr Biochem. 2002;13(5):282-288

21. Wang J, Mazza G. Effects of anthocyanins and other phenolic compounds on the production of tumor necrosis factor alpha in LPS/IFN gamma-activated RAW 264.7 macrophages. J Agric Food Chem. 2002;50(15):4183-4189.

22. Kim H, Han SB, Lee OW, et al. Use of prodigiosin for treating diabetes mellitus. US patent. 6,638,968, USA; 2003
23. Campàs $\mathrm{C}$, Dalmau $\mathrm{M}$, Montaner $\mathrm{B}$, et al. Prodigiosin induces apoptosis of B and T cells from B-cell chronic lymphocytic leukemia. Leukemia. 2003;17(4):746-750.

24. Yada S, Wang Y, Zou Y, et al. Isolation and characterization of two groups of novel marine bacteria producing violacein. Mar Biotechnol. 2007;10(2):128-132.

25. Martz C, Deines P, Boenigk J, et al. Impact of violacein-producing bacteria on survival and feeding of bacterivorousnano flagellates. Appl Environ Microbiol. 2004;70(3):1593-1599.

26. Ferreira CV, Bos CL, Versteeg HH, et al. Molecular mechanism of violacein-mediated human leukemia cell death. Blood. 2004;104(5):14591464.

27. Kodach LL, Bos CL, Durán N, et al. synergistically increases 5-fluorouracil cytotoxicity, induces apoptosis and inhibits Akt-mediated signal transduction in human colorectal cancer cells. Carcinogenesis. 2006;27(3):508-516

28. Sánchez C, Braña AF, Méndez C, et al. Reevaluation of the violacein biosynthetic pathway and its relationship to indolocarbazole biosynthesis. Chem BioChem. 2006;7(8):1231-1240.

29. Nakamura Y, Sawada T, Morita Y, et al. Isolation of a psychrotrophic bacterium from the organic residue of a water tank keeping rainbow trout and antibacterial effect of violet pigment produced from the strain. Biochem Eng J. 2002;12(1):79-86.

30. Konzen M, De Marco D, Cordova CA, et al. Antioxidant properties of violacein: possible relation on its biological function. Bioorg Med Chem. 2006;14(24):8307-8313.

31. Mojib N, Philpott R, Huang JP, et al. Antimycobacterialactivity of in vitro of pigments isolated from Antartic bacteria. Antonie van Leeuwenhoek. 2010;98(4):531-540.

32. Richard C. Chromobacterium violaceum, opportunist pathogenic bacteria in tropical and subtropical regions. Bull Soc Pathol Exot. 1993;86(3):169-173.

33. Chidambaram KV, Zainul AZ, Wan AA. Bacterial pigments and their applications. Process Biochemistry. 2013;48(7):1065-1079.

34. Krishnamurthy KV, Siva R, Senthil TK. Natural dye-yielding plants of Shervaroy Hills of Eastern Ghats. In Proceedings of National Seminar on the Conservation of the Eastern Ghats, Tirupathi, Andra Pardesh; 2002. p. 151-153.

35. Alihosseini F, Ju KS, Lango J, et al. Antibacterial colorants: characterization of prodiginines and their applications on textile materials. Biotechnol Prog. 2008;24(3):742-747.

36. Yusof NZ. Isolation and applications of red pigment from Serratia marcescens. Universiti Teknologi Malaysia, Malaysia; 2008.

37. Shirata A, Tsukamoto $\mathrm{T}$, Yasui $\mathrm{H}$, et al. Isolation of bacteria producing bluish-purple pigment and use for dyeing. Jpn Agric Res $Q$. 2000;34(2):131-140.

38. Kumar A, Vishwakarma HS, Singh J, et al. Microbial Pigments: Production and Their Applications in Various Industries. IJPCBS. 2015;5(1):203-212. 